\title{
SILVER DI- $T$-BUTYL PHOSPHATE, A USEFUL REAGENT IN THE SYNTHESIS OF PHOSPHOLIPIDS. SYNTHESIS OF MIXED-ACID PHOSPHATIDIC ACID AND PHOSPHATIDYL GLYCEROLPHOSPHATE
}

\author{
P. P. M. BONSEN and G. H. DE HAAS \\ Department of Biochemistry, Laboratory of Organic Chemistry, University of Utrecht, \\ Utrecht, The Netherlands
}

Received 3 October 1966

The synthesis of silver di-t-butyl phosphate is described. Using this reagent, mixed-acid phosphatidic acid with one unsaturated fatty acid could be prepared by means of a reaction with a 1,2-diacyl glycerol-3-iodohydrin. The blocking groups could be removed easily with dry hydrogen chloride at low temperatures. Phosphatidyl glycerolphosphate was prepared by means of a double condensation reaction between 1,3-diiodo-2-t-butyl glycerol and the silver salts of 1,2-diacyl glycerol-3-(benzyl)phosphate and of di-t-butyl phosphate. The protecting groups were released by anionic debenzylation and treatment with hydrogen chloride. Some properties and enzymic degradations of the synthesized compounds are discussed.

\section{Introduction}

In the synthesis of phospholipids, only a few phosphate-blocking groups are used. The phenyl group, used by Baer ${ }^{1}$ ) and Verkade ${ }^{2}$ ) for a variety of phospholipids, can be removed only by catalytic hydrogenolysis. Phospholipids with unsaturated fatty acids therefore can not be prepared by this procedure. The benzyl group, introduced by Hessel et al. ${ }^{3}$ ), appeared to be more useful. An advantage of this group is the possibility of removing one benzyl group from phosphotriesters by anionic debenzylation, which was applied in the synthesis of numerous phospholipids ${ }^{4}$ ). In the preparation of phosphatidic acid from benzyl phosphatidic acid, however, the second benzyl group must be released by catalytic hydrogenolysis, making this method also inaccessible for unsaturated compounds.

Efforts in our laboratory to split off both benzyl groups by catalytic hydrogenolysis, after bromination of the unsaturated fatty acids of dibenzyl phosphatidic acid, followed by debromination, were unsuccessful. Hydrolysis of the two benzylesters with liquid hydrobromic acid gave phosphatidic acid, but a part of the unsaturated fatty acid was attacked by the reagent.

Until now, no synthesis of mixed-acid phosphatidic acid has been reported. Owing to the unfeasible preparation of pure mixed acid 1,2-diacyl 
glycerols, this most simple phospholipid has been synthesized only with saturated fatty acids ${ }^{3,5-9}$ ) or two identical unsaturated fatty acids ${ }^{10}$ ). Recently Lapidot and Selinger ${ }^{11}$ ) reported the synthesis of dioleoyl phosphatidic acid from glycerol phosphate.

The exhaustive debenzylation of $p$-substituted benzyl phosphates, which is due to the negative inductive effect of a halogen, nitro- or cyano-group, as described by Miyano ${ }^{12}$ ) and suggested by Verkade ${ }^{2}$ ) as a possible procedure for the synthesis of unsaturated phosphatidic acid, appeared to be a useful method, but for higher unsaturated fatty acids a milder procedure was wanted.

The $t$-butyl group, an excellent protecting group for hydroxyl and carboxyl functions has been reported as phosphate ester only in the case of simple phosphates ${ }^{13}$ ). The mild conditions for its removal made this group favourable for our purpose. The silver salt of di-t-butyl phosphate (II), prepared from di-t-butyl phosphate via the barium salt of di-t-butyl phosphate, appeared to be very useful in the synthesis of phosphatidic acid. By means of a reaction of II (scheme 1) with a 1,2-diacyl glycerol-3-iodohydrin (I) a phosphotriester (III) was obtained from which the two $t$-butyl groups were removed by anhydrous hydrogen chloride in chloroform at $0{ }^{\circ} \mathrm{C}$, giving phosphatidic acid (Iv) in a fairly good yield.

A second application of this new reagent is the synthesis of phosphatidyl glycerolphosphate. This phospholipid was first detected as an intermediate in the biosynthesis of phosphatidyl glycerol in rat liver by Kiyasu et al. ${ }^{14}$ )

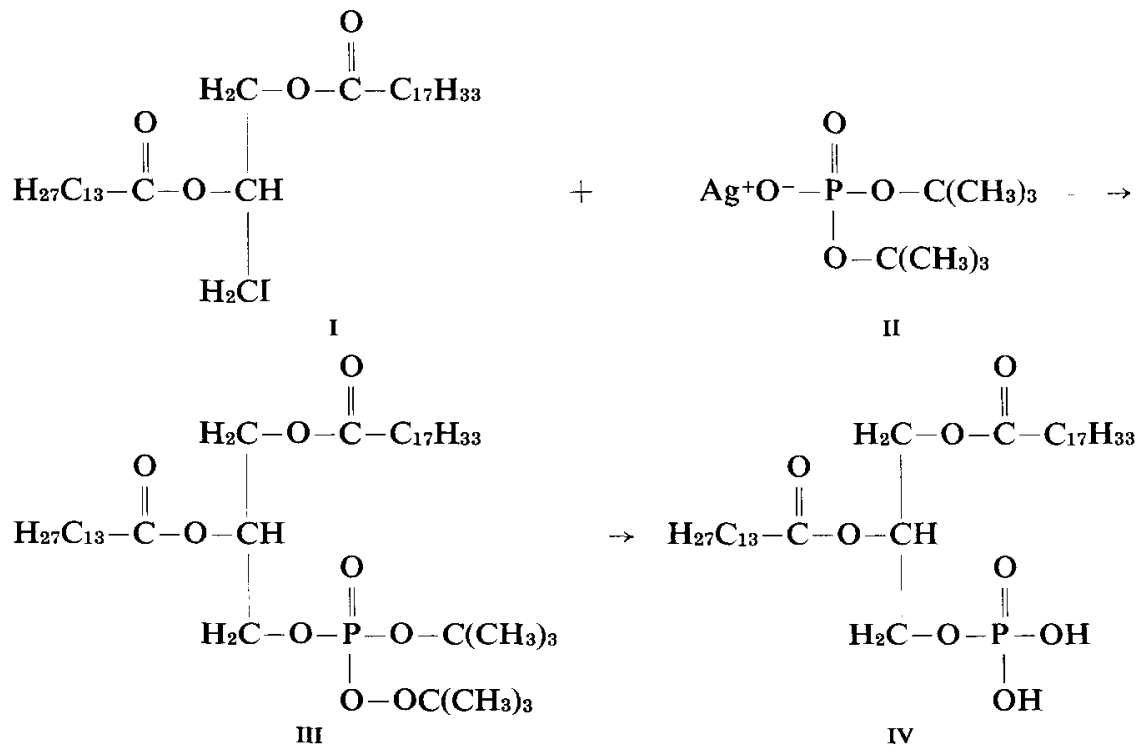

Scheme 1. Synthesis of 1-oleoyl-2-myristoyl-3-phosphatidic acid. 
and afterwards also found in bacteria ${ }^{15}$ ). Coulon-Morelec et al. ${ }^{16}$ ) observed the non-enzymic hydrolysis of cardiolipin in acidic media and found phosphatidyl glycerolphosphate as one of the main degradation products. De Haas et al.17) obtained this compound as an intermediate in the hydrolysis of synthetic diphosphatidyl glycerol and natural ox-heart cardiolipin with phospholipase $\mathrm{C}$ from Bacillus cereus. A diether analogue of phosphatidyl glycerolphosphate was isolated from Halobacterium cutirubrum by Kates et al. ${ }^{18}$ ).

The synthesis of phosphatidyl glycerolphosphate was effected by means of a reaction between the silver salt of a 1,2-diacyl-glycerol-3-(0-benzyl) phosphate (scheme 2-v) and 1,3-diiodo-2-t-butyl glycerol (vI). Condensation

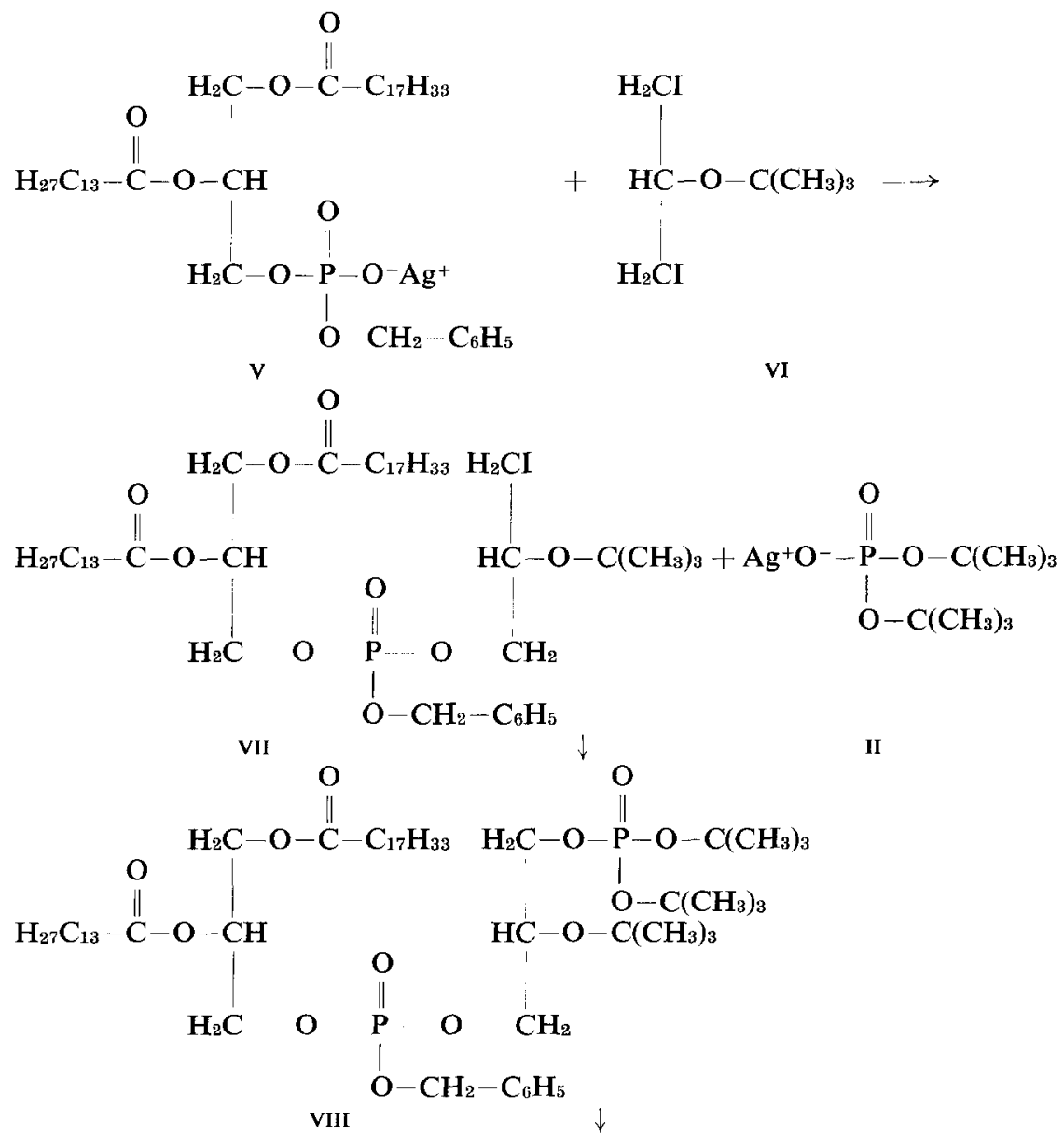

Scheme 2. Synthesis of 1-oleoyl-2-myristoyl-glycerol-3-phosphoryl-(rac)-1'-glycerol3'-phosphate. 


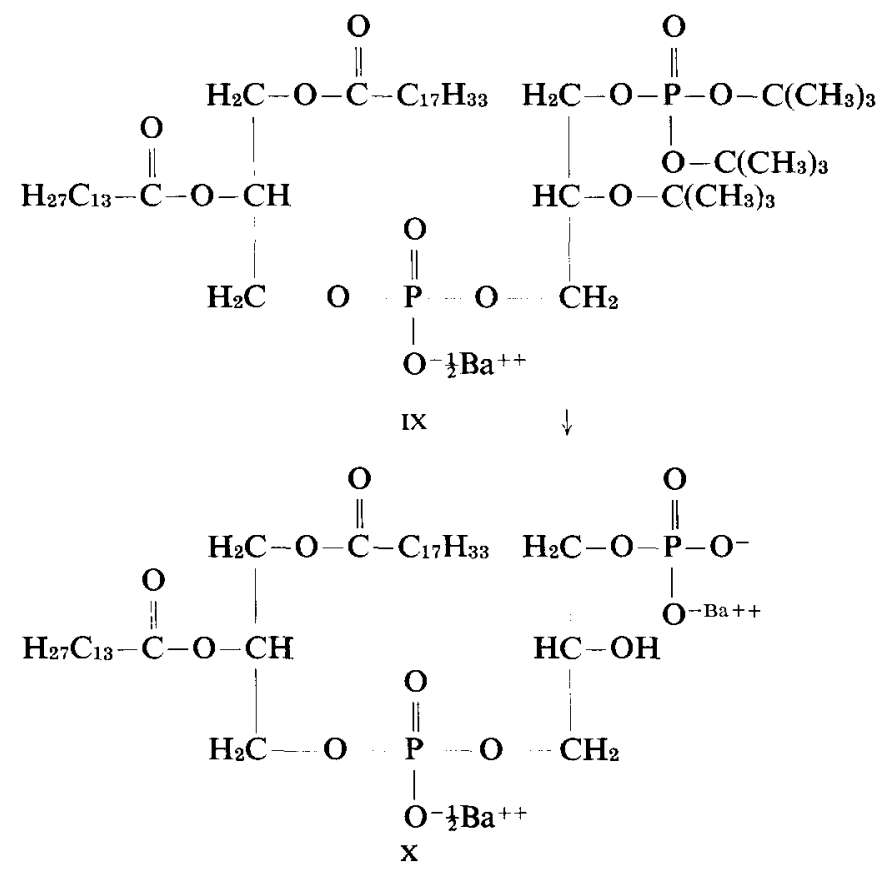

Scheme 2, continued.

with the silver salt of dibenzyl phosphate and removal of the protecting groups with liquid hydrogen bromide yielded phosphatidyl glycerolphosphate as described in a previous publication ${ }^{17}$ ), but a part of the unsaturated fatty acid was attacked by the reagent. Therefore preference was given to a reaction with the silver salt of di-t-butyl phosphate (II) instead of the silver salt of dibenzyl phosphate, giving the phosphotriester viII. The blocking groups were released by anionic debenzylation and treatment with dry hydrogen chloride, giving phosphatidyl glycerolphosphate (x) after purification on silica as a pure product.

\section{EXPERIMENTAL PART}

\section{Methods}

Micro-analyses were carried out in the Analytical Department of the Laboratory of Organic Chemistry, University of Groningen. Melting points were determined on a Kofler hot plate and are uncorrected. Optical rotations were measured in a Lichtelektrisches Präzisions polarimeter $0.005^{\circ}$, Carl Zeiss. The purity of intermediates and endproducts was checked by paper chromatography and by thin-layer chromatography on silica gel as de- 
scribed previously ${ }^{19}$ ). Especially for the acidic phospholipids, silica plates impregnated with oxalic acid were used, with the solvent system chloroformmethanol-conc. hydrochloric acid $(87: 13: 0.5, \mathrm{v} / \mathrm{v} / \mathrm{v})$. Detection was carried out by established procedures. After chromatographic separation and methanolysis, quantitative analyses of the fatty acids, present in the various lipids, were carried out by gas liquid chromatography as described earlier ${ }^{20}$ ). Mild alkaline hydrolysis products, obtained according to the procedures developed by Dawson et al. ${ }^{21,22}$ ) were investigated by paper chromatography on Whatman no. 1 paper with propanol-ammonia-water $(6: 3: 1, \mathrm{v} / \mathrm{v} / \mathrm{v})$. Incubation conditions with phospholipase A (E.C. 3.1.1.4) from Crotalus adamanteus, with phospholipase C (E.C. 3.1.4.3) from Bacillus cereus and with phospholipase D (E.C. 3.1.4.4) from savoy-cabbage have been given in earlier publications ${ }^{17,23}$ ).

\section{Materials}

Di- $t$-butyl phosphite was prepared according to the method of Young ${ }^{24}$ ) and Cherbuliez et al. ${ }^{13}$ ). 1,3-diiodo-2-t-butyl glycerol (VI) was synthesized as described previously ${ }^{25}$ ). 1,2-diacyl-glycerol-3-iodohydrins and the silver salt of 1-oleoyl-2-myristoyl-glycerol-3-(0-benzyl)phosphate were prepared as described for other homologues 26,27 ). The synthesis of the silver salt of di-pbromo-benzylphosphate was carried out according to Baddiley et al. ${ }^{28}$ ). The condensation of this product with a 1,2-diacyl glycerol-3-iodohydrin and the anionic debenzylation were carried out by established procedures ${ }^{26}$ ).

\section{Barium salt of di-t-butyl phosphate}

Oxidation of di-t-butyl phosphite with potassium permanganate was performed as described by Brown and Hammond ${ }^{8}$ ). The phosphate obtained was treated with a solution of saturated barium hydroxide. The excess was precipitated by bubbling carbondioxide through the solution. The precipitate was filtered off and the clear solution evaporated in vacuo. The residue was crystallized from methanol-acetone at $-15^{\circ} \mathrm{C}$. The barium salt was obtained as a white solid in a yield of $43 \%$ with m.p. $205-207{ }^{\circ} \mathrm{C}$ (decomposition).
Found

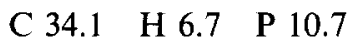
Calc. for $\mathrm{C}_{8} \mathrm{H}_{18} \mathrm{Ba}_{0.5} \mathrm{O}_{4} \mathrm{P}(\mathrm{M}=277.89) \mathrm{C} 34.57 \mathrm{H} 6.50 \mathrm{P} 11.14$

\section{Silver salt of di-t-butyl phosphate (II)}

To a solution of the barium salt in water was added a solution of an equivalent amount of silver sulphate in water. The precipitated barium sulphate was centrifuged off, and the clear supernatant evaporated in vacuo. Crystallization of the remaining material from methanol-acetone 
at $-15{ }^{\circ} \mathrm{C}$ yielded the silver salt as white crystals in a yield of $75 \%$. m.p. $185-187^{\circ} \mathrm{C}$.

Found

$$
\begin{array}{llll}
C & 30.7 & \text { H } 5.8 & \text { P } 9.7
\end{array}
$$

Calc. for $\mathrm{C}_{8} \mathrm{H}_{18} \mathrm{AgO}_{4} \mathrm{P}(\mathrm{M}=317.09) \mathrm{C} 30.30 \mathrm{H} 5.75 \mathrm{P} 9.76$

\section{1-oleoyl-2-palmitoyl-glycerol-3-phosphate (phosphatidic acid)}

$1.2 \mathrm{~g}$ of 1-oleoyl-2-palmitoyl-glycerol-3-(0-p-bromobenzyl) phosphoric acid was dissolved in $50 \mathrm{ml}$ of cellosolve with $0.45 \mathrm{~g}$ of barium iodide and heated at $125^{\circ} \mathrm{C}$ for $2 \mathrm{hr}$. After cooling of the solution a precipitate was formed, which was centrifuged and washed with acetone. Thin-layerchromatograms showed a conversion to phosphatidic acid of $60-70 \%$. The precipitate was dissolved in ether and treated with ice-cold $0.5 \mathrm{~N}$ sulphuric acid. The acidic phosphatidic acid was chromatographed on silica as rapidly as possible. The collected fractions were converted into the barium salt immediately and crystallized twice from pentane-acetone. The product obtained (yield about $50 \%$ ) revealed one spot on thin-layer chromatograms and paper chromatograms with the same $\mathbf{R}_{\mathbf{F}}$ value as authentic phosphatidic acid. Fatty acid analysis of this product gave a ratio of palmitic to oleic acid of 0.993. Confirmation of the stereochemical nature of this phosphatidic acid was achieved by means of hydrolysis with snake-venom phospholipase $\mathrm{A}$. A complete conversion into a lyso compound and free fatty acid demonstrated clearly, taking in consideration the stereo-specific action of this enzyme ${ }^{29}$ ), that this phosphatidic acid is identical in all respects to 1-oleoyl-2-palmitoylglycerol-3-phosphate.

\section{1-oleoyl-2-myristoyl-glycerol-3-phosphate (Iv) (phosphatidic acid)}

The condensation of the silver salt of di-t-butyl phosphate (II) and 1-oleoyl2-myristoyl-glycerol-3-iodohydrin (I) was effected in dry chloroform at boiling temperature for $1 \mathrm{hr}$. The precipitated silver iodide was removed by centrifugation. The supernatant was evaporated in vacuo, dissolved in pentane and subsequently washed with a solution of sodium bicarbonate and water. After drying over sodium sulphate, the pentane solution was evaporated and the oily residue dried in vacuo over $\mathrm{KOH}$. This phosphotriester (III) was not purified, because of the lability of the $t$-butylesters.

This material was dissolved in dry chloroform (freshly distilled over $\mathrm{P}_{2} \mathrm{O}_{5}$ ) through which, under cooling at $0{ }^{\circ} \mathrm{C}$, a stream of anhydrous hydrogen chloride was passed for $1 \mathrm{hr}$. After evaporation of the chloroform, the phosphatidic acid was converted into the barium salt with barium acetate in methanol-water $(2: 1, \mathrm{v} / \mathrm{v})$. The barium salt was chromatographed on silica with chloroform-methanol $(95: 5, \mathrm{v} / \mathrm{v})$ as eluent. The phosphatidic acid was crystallized as the barium salt from chloroform-methanol at $-15^{\circ} \mathrm{C}$, and 
obtained as a white solid in a yield of $70 \%$ m.p. $>360{ }^{\circ} \mathrm{C} .[\alpha]_{20}^{\mathrm{D}}=+12.4^{\circ}$ ( $c 8$ in chloroform-methanol $(95: 5, \mathrm{v} / \mathrm{v})$. Fatty acid analysis revealed a proportion oleic acid to myristic acid of 1.01 . This compound was partly converted into the di-sodium salt. m.p. $208-210^{\circ} \mathrm{C}$. $[\alpha]_{\mathrm{D}}^{20}=+5.70^{\circ}$ (c 11 in chloroform). Found P, 4.3; calculated P, 4.32. Another part was converted into the acid form (IV) with $0.5 \mathrm{~N}$ sulphuric acid and crystallized from acetone. m.p. $61-63{ }^{\circ} \mathrm{C} .[\alpha]_{\mathrm{D}}^{18}=+2.05^{\circ}$ (c 6 in chloroform).

Found

$\begin{array}{lll}C & 64.9 & \text { H } 10.4 \\ \text { P } 4.5\end{array}$

Calc. for $\mathrm{C}_{35} \mathrm{H}_{67} \mathrm{O}_{8} \mathrm{P}(\mathrm{M}=646.86) \mathrm{C} 64.98 \mathrm{H} 10.41 \mathrm{P} 4.78$

1-oleoyl-2-myristoyl-glycerol-3-phosphoryl-(rac)-1'-(3'-iodo-2'-t-butyl) glycerol

$3.5 \mathrm{~g}$ of the silver salt $\mathrm{v}$ was reacted with $3.2 \mathrm{~g}$ (100\% excess) of $1,3 \mathrm{di}$ iodo-2- $t$-butyl glycerol (VI) in toluene. After heating at $120^{\circ} \mathrm{C}$ for $2 \mathrm{hr}$, the mixture was cooled, the precipitated silver iodide discarded and the solution evaporated in vacuo. The residue was dissolved in benzene and chromatographed over silica in the dark. Elution with $40 \%$ ether in benzene yielded $1.74 \mathrm{~g}$ of VII as a colourless viscous oil $\left(47^{\circ}\right) \cdot[\alpha]_{\mathrm{D}}^{20}=+1.70^{\circ}(c 10$ in chloroform).

$\begin{array}{llllll}\text { Found } & \text { C } 60.2 & \text { H } 9.1 & \text { I } 13.3 & \text { P } 2.9\end{array}$

Calc. $\mathrm{C}_{49} \mathrm{H}_{86} \mathrm{IO}_{9} \mathrm{P}(\mathrm{M}=977.05) \mathrm{C} 60.23 \mathrm{H} 8.87$ I 12.99 P 3.17

1-oleoyl-2-myristoyl-glycerol-3-phosphoryl-(rac)-1'-glycerol-3'-phosphate (x) (phosphatidyl glycerolphosphate)

The foregoing product VII was reacted with silver di-t-butyl phosphate (II) in toluene at $110^{\circ} \mathrm{C}$ for $30 \mathrm{~min}$. The precipitated silver iodide was removed by centrifugation. The supernatant was washed with a solution of sodium bicarbonate and water. After drying over sodium sulphate the solvent was evaporated and the residue (VIII) immediately debenzylated with barium iodide in acetone. The precipitated barium salt IX, which already showed some hydrolysis of the $t$-butylester, was dried in vacuo over $\mathrm{KOH}$ and dissolved in dry chloroform. A stream of anhydrous hydrogen chloride was passed through the solution at $0{ }^{\circ} \mathrm{C}$ for $1 \mathrm{hr}$ in order to remove the three $t$-butyl groups. After evaporation of the solvent, the residue was converted into the barium salt with barium acetate in methanol-water $(2: 1, \mathrm{v} / \mathrm{v})$. This material was chromatographed over silica with chloroform-methanol mixtures as eluents, yielding $\mathrm{x}$ as a white solid $(43 \%)$ after crystallization from chloroform-acetone. m.p. $>300{ }^{\circ} \mathrm{C} .[\alpha]_{\mathrm{D}}^{20}=+4.70^{\circ}$ (c 7 in chloroform-methanol $(9: 1, v / v)$. The ratio oleic acid-myristic acid revealed to be 1.0 .

Found

$\begin{array}{lll}\text { C } 45.1 & \text { H } 6.8 & \text { P } 5.9\end{array}$

Calc. for $\mathrm{C}_{38} \mathrm{H}_{71} \mathrm{Ba}_{1.5} \mathrm{O}_{13} \mathrm{P}_{2}(\mathrm{M}=1003.99) \mathrm{C} 45.45 \mathrm{H} 7.13 \mathrm{P} 6.17$ 


\section{Properties and enzymic degradations}

Both synthetic products (phosphatidic acid and phosphatidyl glycerolphosphate) appeared as distinct spots on paper chromatograms impregnated with silica with the solvent system of Marinetti et al. $\left.{ }^{30}\right)\left(\mathrm{R}_{\mathrm{F}}=0.85-0.90\right.$ and 0.45 respectively). On thin-layer chromatograms good spots could only be obtained by using oxalic acid impregnated plates with chloroform-methanolconc. hydrochloric acid $(87: 13: 0.5, \mathrm{v} / \mathrm{v} / \mathrm{v})$ as solvent system. Alkaline hydrolysis of phosphatidic acid according to the procedure of Dawson et al. ${ }^{21,22}$ ) yielded only glycerol-3-phosphate as water soluble product. After alkaline hydrolysis phosphatidyl glycerolphosphate gave one water soluble product identical with a synthetically prepared reference of glycerylphosphoryl glycerolphosphate $\left(\mathrm{R}_{\mathrm{F}} 0.30\right)$ and with the hydrolysis products of phosphatidyl glycerolphosphate obtained by phospholipase $\mathrm{C}$ treatment of natural cardiolipin and synthetic diphosphatidyl glycerol ${ }^{17}$ ). On potentiometric titration of $11.2 \mu \mathrm{mol}$ of phosphatidic acid (acid form) dissolved in tetrahydrofuranwater $(1: 1, \mathrm{v} / \mathrm{v}) 10.8 \mu$ eq. alkali were consumed by the strong $\left(p \mathrm{~K}_{1}=3.9\right)$ and $11.2 \mu$ eq. alkali by the weak acidic group $\left(p \mathrm{~K}_{2}=8.3\right)$.

Infrared spectra of the synthesized phospholipids are given in fig. 1. Only

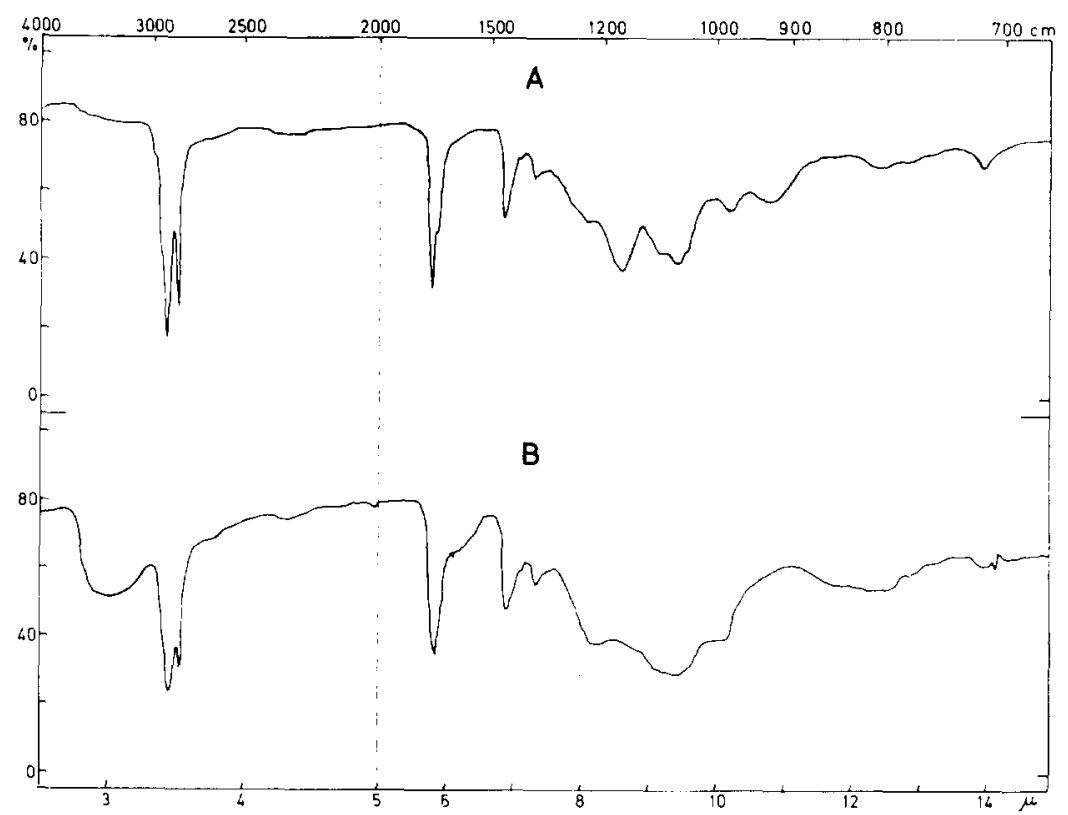

Fig. 1. Infrared spectra. A Beckman IR-8 spectrophotometer was used. Both samples were spread as a thin film on a $\mathrm{KBr}$ disc. Ordinate: \% transmission, abscissa: wavelength. A: synthetic phosphatidic acid as barium salt. B: synthetic phosphatidyl glycerolphosphate as barium salt. 
the spectrum of natural phosphatidic acid is mentioned in the literature ${ }^{31}$ ). The differences between this spectrum and that of synthetic phosphatidic acid are predominantly the 7.10 and $3.15 \mu$ absorption which must be attributed to the ammonium salt of the former.

Phosphatidic acid and phosphatidyl glycerolphosphate were both susceptible to the action of phospholipase A from Crotalus adamanteus. The incubations were carried out in the presence of stearyl phosphorylcholine as activating agent. Both products were completely hydrolysed into lyso compounds and free fatty acids. Analysis of the fatty acids demonstrated that only the fatty acid at the 2-position was released from both synthetic compounds.

Phospholipase C from Bacillus cereus was not able to hydrolyse phosphatidic acid. Phosphatidyl glycerolphosphate could be hydrolysed only when zinc ions were added, giving a 1,2-diglyceride and a water soluble product. Investigation of the aqueous phase of the incubation mixture showed the identity of this substance with 1,3-diphosphoglycerol in the solvent system applied by LeCocq and Ballou ${ }^{32}$ ) using synthetic 1,2- and 1,3-diphosphoglycerol as reference compounds.

Incubation of synthetic phosphatidyl glycerolphosphate with a cell free enzyme extract of Escherichia coli according to Kanfer and Kennedy ${ }^{15}$ ) yielded phosphatidyl glycerol, identical with a synthetic specimen, and inorganic phosphate.

\section{Acknowledgements}

The authors are indebted to Dr. J. H. van der Maas (Laboratory of Analytical Chemistry, University of Utrecht, Director Professor Dr. Ir. J. Smittenberg) for infrared absorption measurements. The collaboration of miss G. J. Westerhuis is highly appreciated.

\section{References}

1) E. Baer, J. Am. Oil Chem. Soc. 42 (1965) 257

2) P. E. Verkade, Bull. Soc. Chim. France (1963) 1993

3) L. W. Hessel, I. D. Morton, A. R. Todd and P. E. Verkade, Rec. Trav. Chim. 73 (1954) 150

4) L. L. M. van Deenen and G. H. de Haas, Advances in lipid research, Academic press inc., New York, Vol. 2, 1964, p. 167

5) J. H. Uhlenbroek and P. E. Verkade, Rec. Trav. Chim. 72 (1953) 395

6) E. Baer, J. Biol. Chem. 189 (1951) 235

7) R. L. Baylis, T. H. Bevan and T. Malkin, Chem. Ind. (London) (1955) 67

8) D. M. Brown and P. R. Hammond, J. Chem. Soc. (1960) 4229

9) N. L. Stanacev and M. Kates, Can. J. Biochem. Physiol. 38 (1960) 297

10) E. Baer and D. Buchnea, Arch. Biochem. Biophys. 78 (1958) 294

11) Y. Lapidot and Z. Selinger, J. Am. Chem. Soc. 87 (1965) 5522

12) M. Miyano, J. Am. Chem. Soc. 77 (1955) 3524 
13) E. Cherbuliez, R. Prince and J. Rabinowitz, Helv. Chim. Acta 47 (1964) 1653

14) J. Y. Kiyasu, R. A. Pieringer, H. Paulus and E. P. Kennedy, J. Biol. Chem. 238 (1963) 2293

15) J. Kanfer and E. P. Kennedy, J. Biol. Chem. 239 (1964) 1720

16) M. J. Coulon-Morelec, M. Faure and J. Maréchal, Bull. Soc. Chim. Biol. 44 (1962) 171

17) G. H. de Haas, P. P. M. Bonsen and L. L. M. van Deenen, Biochim. Biophys. Acta $116(1966) 114$

18) M. Kates, L. S. Yengoyan and P. S. Sastry, Biochim. Bipohys. Acta 98 (1965) 252

19) F. J. M. Daemen, G. H. de Haas and L. L. M. van Deenen, Rec. Trav. Chim. 82 (1963) 487

20) L. L. M. van Deenen, G. H. de Haas and C. H. Th. Heemskerk, Biochim. Biophys. Acta 67 (1963) 295

21) R. M. C. Dawson, Biochem. J. 75 (1960) 45

22) R. M. C. Dawson, N. Hemington and J. B. Davenport, Biochem. J. 84 (1962) 497

23) F. Haverkate and L. L. M. van Deenen, Biochim. Biophys. Acta 84 (1964) 106

24) R. W. Young, J. Am. Chem. Soc. 75 (1953) 4620

25) G. H. de Haas and L. L. M. van Deenen, Rec. Trav. Chim. 84 (1965) 436

26) G. H. de Haas and L. L. M. van Deenen, Rec. Trav. Chim. 80 (1961) 951

27) G. H. de Haas and L. L. M. van Deenen, Rec. Trav. Chim. 82 (1963) 1163

28) J. Baddiley, V. M. Clark, J. J. Michalski and A. R. Todd, J. Chem. Soc. (1949) 815

29) L. L. M. van Deenen and G. H. de Haas, Biochim. Biophys. Acta 70 (1963) 538

30) G. V. Marinetti, J. Erbland and E. Stotz, J. Biol. Chem. 233 (1958) 562

31) G. Rouser, G. Kritchevsky, D. Heller and E. Lieber, J. Am. Oil Chem. Soc. 40 (1963) 425

32) J. LeCocq and C. E. Ballou, Biochemistry 3 (1964) 976 